PREPARED FOR THE U.S. DEPARTMENT OF ENERGY, UNDER CONTRACT DE-AC02-76CH03073

PPPL-4006

PPPL-4006

UC-70

Comparison and Evaluation of Various Tritium

Decontamination Techniques and Processes

by

C.A. Gentile, S.W. Langish,

C.H. Skinner, and L.P. Ciebiera

September 2004

$N_{\substack{\text { PRInCETOn PLASMA } \\ \text { PHYSIES LABORATORY }}}^{D}$

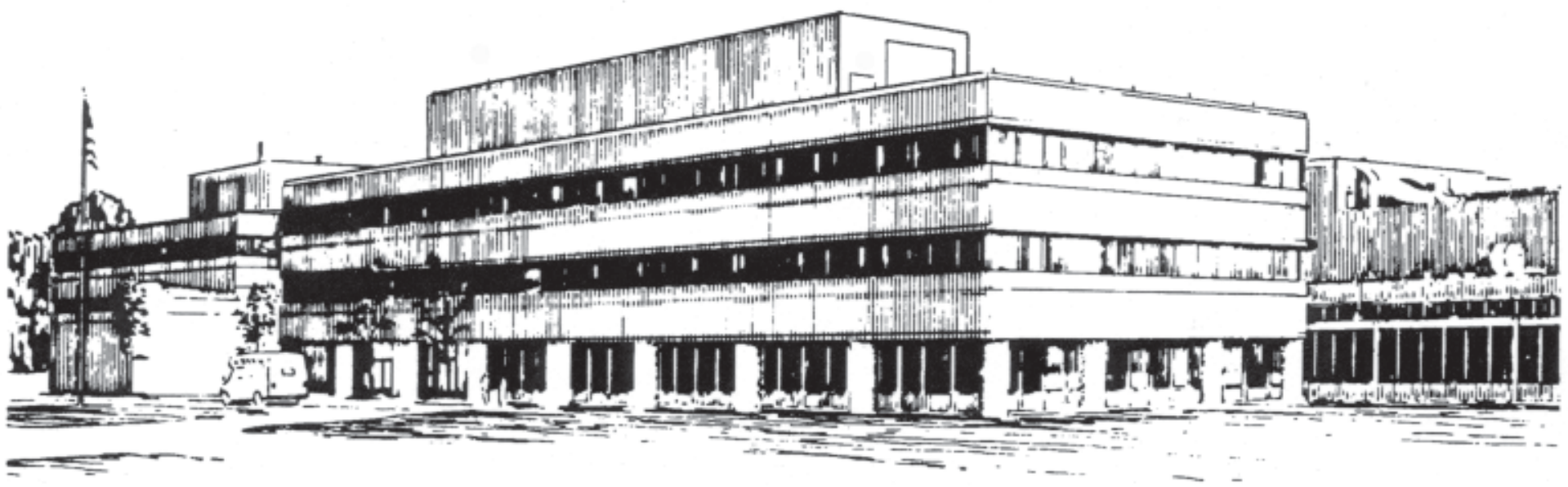

PRINCETON PLASMA PHYSICS LABORATORY PRINCETON UNIVERSITY, PRINCETON, NEW JERSEY 


\section{PPPL Reports Disclaimer}

This report was prepared as an account of work sponsored by an agency of the United States Government. Neither the United States Government nor any agency thereof, nor any of their employees, makes any warranty, express or implied, or assumes any legal liability or responsibility for the accuracy, completeness, or usefulness of any information, apparatus, product, or process disclosed, or represents that its use would not infringe privately owned rights. Reference herein to any specific commercial product, process, or service by trade name, trademark, manufacturer, or otherwise, does not necessarily constitute or imply its endorsement, recommendation, or favoring by the United States Government or any agency thereof. The views and opinions of authors expressed herein do not necessarily state or reflect those of the United States Government or any agency thereof.

\section{Availability}

This report is posted on the U.S. Department of Energy's Princeton Plasma Physics Laboratory Publications and Reports web site in Fiscal Year 2004. The home page for PPPL Reports and Publications is: http://www.pppl.gov/pub_report/

DOE and DOE Contractors can obtain copies of this report from:

U.S. Department of Energy

Office of Scientific and Technical Information

DOE Technical Information Services (DTIS)

P.O. Box 62

Oak Ridge, TN 37831

Telephone: (865) 576-8401

Fax: (865) 576-5728

Email: reports@adonis.osti.gov

This report is available to the general public from:

National Technical Information Service

U.S. Department of Commerce

5285 Port Royal Road

Springfield, VA 22161

Telephone: $1-800-553-6847$ or

(703) $605-6000$

Fax: (703) 321-8547

Internet: http://www.ntis.gov/ordering.htm 


\title{
Comparison and Evaluation of Various Tritium Decontamination Techniques and Processes
}

\author{
C.A. Gentile, S. W. Langish, C. H. Skinner, L. P. Ciebiera \\ Princeton Plasma Physics Laboratory, Princeton University, P.O. Box 451, James Forrestal Campus, Princeton, NJ 08543 \\ USA, Email: cgentile@pppl.gov
}

\begin{abstract}
In support of fusion energy development, various techniques and processes have been developed over the past two decades for the removal and decontamination of tritium from a variety of items, surfaces, and components. The motivational force for tritium decontamination by chemical, physical, mechanical, or a combination of these methods, is driven by two underlying forces. The first of these motivational forces is safety. Safety is paramount to the established culture associated with fusion energy. The second of these motivational forces is cost. In all aspects, less tritium contamination equals lower operational and disposal costs. This paper will discuss and evaluate the various processes employed for tritium removal and decontamination.
\end{abstract}

\section{INTRODUCTION}

Tritium Decontamination of various materials and components associated with fusion energy development has proceeded forward over the past twenty years. The motivation for tritium removal, in pursuit of fusion energy, falls into four categories. The first of these is to remove tritium from components in a manner to reduce tritium contamination for radiological protection purposes. The second is to remove tritium in a fashion such that an item can be reused in a non-tritium environment. This is typically defined as "free releasing" components for use in non-radiological areas. The third is to remove tritium in a manner such that a specific inventory limit can be maintained. This is critical in maintaining site limits in compliance with regulatory requirements, or for maintaining operational control of material (tritium) in-process by reducing inventory "bottlenecks" in the system. The ability to move tenaciously held tritium to a more useful area within the tritium boundary has additional value. The fourth category is to remove tritium from items such that they may be disposed of in a less restrictive fashion. The underlying common factor for the removal of tritium in all four of these categories is safety and cost. The need to remove or reduce tritium for radiological protection purposes, in addition to personnel safety, is in part to attenuate the cost of operating a facility due to increased engineering and radiological controls. The motivation for removing tritium from a component, which can be "free released" and employed in a non-tritium environment, is to conserve resources by using a device/component over again in a less restrictive, non-radiological, or low radiological environment. The motivation for the removal of tritium associated with inventory control, in addition to technical safety concerns, is to reduce site costs related to engineering controls, site boundary doses, environmental impacts, mitigating systems, and facility design. The driving force associated with the removal of tritium for the purpose of disposal is directly related to the cost of regulatory compliance, transportation, packaging and handling requirements. In countries where fusion energy is being developed, regulatory compliance and disposal cost of tritiated items/components can comprise a significant fraction of the operating budget of the facility. In addition, costs associated with transportation and disposal typically outpaces the rate of inflation.

The cost of tritium is relatively inexpensive at several dollars per Curie. However, the cost of disposal and management of tritiated items can be as much as several orders of magnitude higher in fusion facilities, thus costing many thousands of dollars to dispose of the same Curie which cost only several dollars to procure.

\section{TRITIUM REMOVAL}

The removal of tritium from components is typically performed by chemical, physical, and/or mechanical techniques.

Chemical techniques include oxidative decontamination processes, or chelating agents, which work by combining with tritium in a fashion that is effective in reducing surface and near-surface tritium [1]. Figure 1 depicts a chemical oxidative system for removing tritium from "soft waste" items [2]. Empirical measurements $\left(\Delta \mathrm{T}^{2}\right.$ concentrations $)$ employing this system have achieved a tritium Decontamination Factor (DF) of greater than 100 . This system is capable of processing up to $20 \mathrm{~kg}$ of soft waste in a batch mode. The process container is loaded with various components of Personal Protective Equipment (PPE). The device rotates the reaction chamber at approximately $10 \mathrm{rpm}$ while ozone gas is fed into the stainless steel container. An 
additional feature of the device is that, in addition to reducing tritium from these soft wastes, is a size reduction due to the interaction of ozone with various plastic and polymer-based materials resulting in a shredding effect.

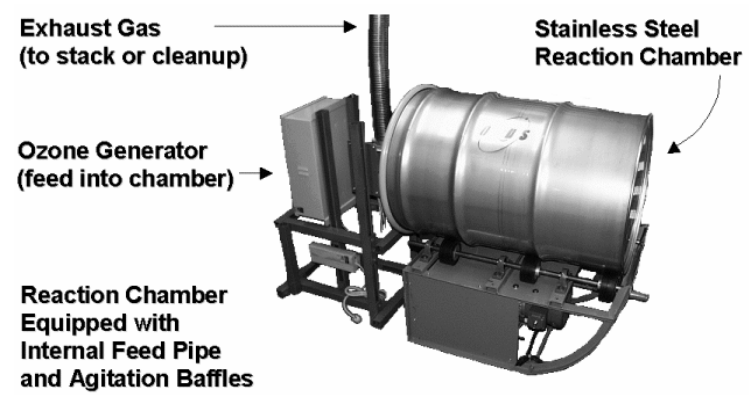

Fig. 1. Rotary Oxidative Tritium Decontamination System

Similar results have been achieved with hydrogen peroxide $\left(\mathrm{H}_{2} \mathrm{O}_{2}\right)$ solutions at concentrations of $3 \%$ at room temperature $[2,3]$. In these applications components are immersed in a hydrogen peroxide bath and are subjected to a several hours of immersion in the $\mathrm{H}_{2} \mathrm{O}_{2}$ decontamination cocktail. Table I depicts survey results prior to and after $\mathrm{H}_{2} \mathrm{O}_{2}$ decontamination of TFTR RF feed-throughs. These devices, which consist of stainless steel, copper, and ceramic material, were successfully decontaminated for use in a non-tritiated environment. The cost savings associated with reusing these components in another (non-tritium environment) fusion energy device at PPPL saved the laboratory approximately $\$ 500,000$.

TABLE I. $\quad \mathrm{H}_{2} \mathrm{O}_{2}$ Decontamination of TFTR RF Feed-through Components

\begin{tabular}{|c|c|c|}
\hline $\begin{array}{l}\text { RF Feed-through } \\
\text { Survey Location }\end{array}$ & $\begin{array}{r}\text { Before Decon } \\
\text { Bq/100 } \mathrm{cm}^{2}\end{array}$ & $\begin{array}{r}\text { After Decon } \\
\text { Bq/100 } \mathbf{c m}^{2}\end{array}$ \\
\hline Outside Ctr. Cond. & 16973.90 & $\overline{0.85}$ \\
\hline Inside Ctr. Cond. & 1355.85 & 1.08 \\
\hline Outside Outer Cond. & 44.97 & 0.50 \\
\hline Conductor Area & 15481.93 & 0.80 \\
\hline Main Body Seal Area & 1393.50 & 0.65 \\
\hline
\end{tabular}

Physical decontamination methods include ovens, lasers, and burners to remove surface and near-surface tritium contamination by raising the surface and bulk temperature of the material being decontaminated. This technology works for a variety or materials and geometries in a fashion to remove tritium from a large distributed surface to a more concentrated area where it can be disposed of or redeployed after processing. These technologies are useful in the removal of tritium from first wall materials and have been shown to be highly effective for the removal of tritium from co-deposited and imbedded tritium in graphite tiles. The use of bake-out ovens provides a powerful tool for removing tritium from various metal, ceramic components and graphite tiles. These types of ovens typically are operated at nominal temperatures of $350-500{ }^{\circ} \mathrm{C}$. Bake-out ovens for tritium decontamination use have been very successful (for small components) in removing tritium from surface and the near-surface matrices.

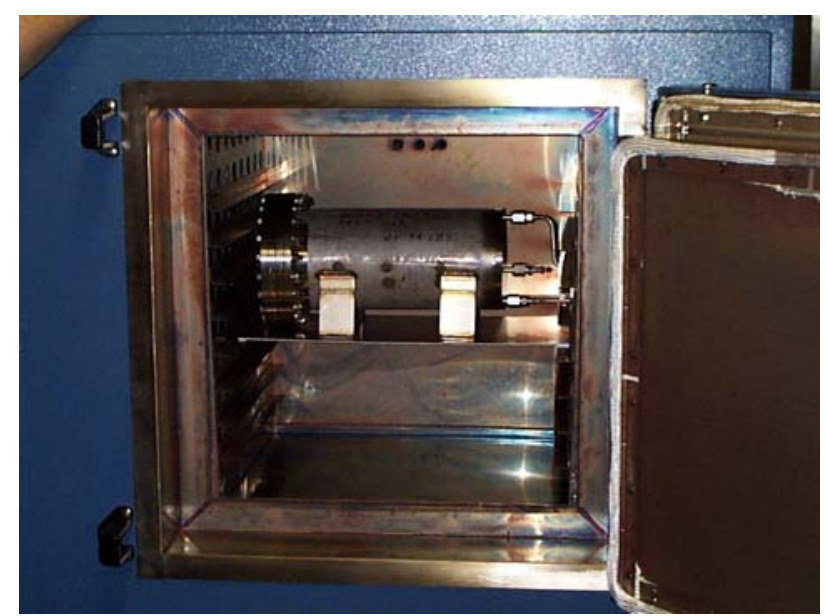

Fig. 2. Tritium Decontamination Bake-out Oven

The Nd:YAG laser configuration shown in Figure 3 was deployed at PPPL and was successful in removing up to $87 \%$ of tritium from TFTR and JET co-deposited layers from graphite tiles $[4,5]$. In addition to rapidly heating the surface of the tile to approximately $2000{ }^{\circ} \mathrm{C}$, in a rastering fashion, this process does not produce tritium oxide (HTO) and can be completely performed in vacuum.

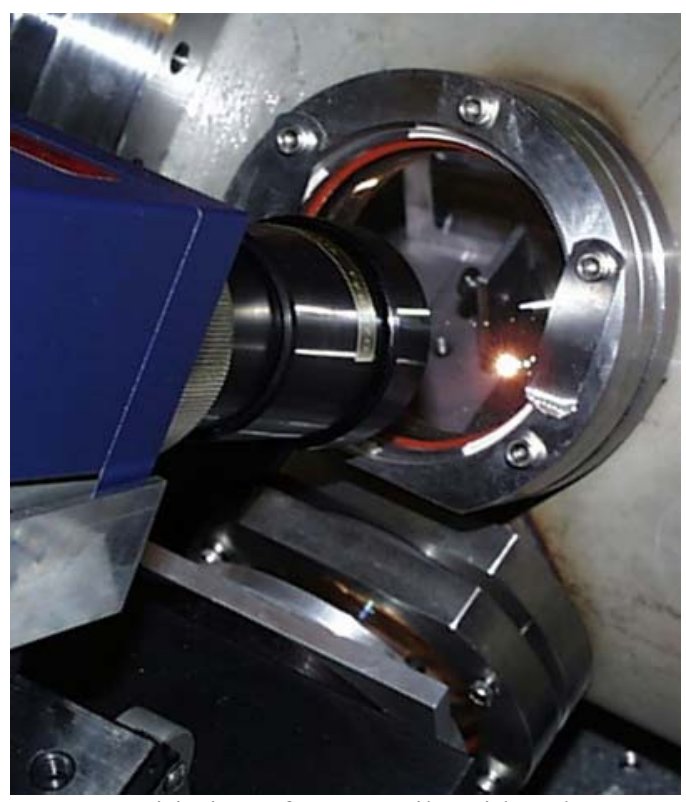

Fig. 3. Detritiation of TFTR Tile with Nd:Yag Laser 
A developing technique for the removal of tritium from graphite tiles is the use of a oxygen-methane burner. In this application a open flame is deployed on the surface of the tile raising the temperature of the heated material to approximately $1000{ }^{\circ} \mathrm{C}$. Empirical measurements collected at PPPL during these experiments, which were performed in collaboration with United Kingdom Atomic Energy Authority (UKAEA) and Tritium Laboratory Karlsruhe (TLK), have resulted in DF's on JET tile surfaces greater than 1000 , and within the tile bulk greater than 60 was realized.

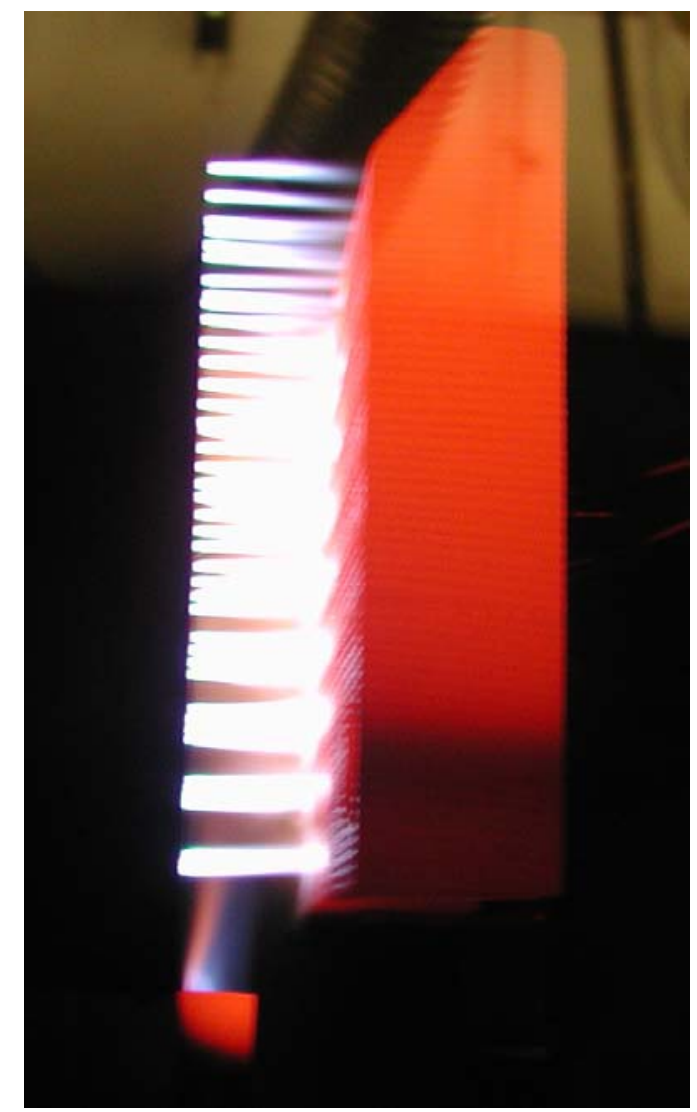

Fig. 4 JET Tile Oxy-Methane Burner Experiment

Mechanical methods include the removal of tritium contamination which includes cutting devices, $\mathrm{CO}_{2}$ pellet ablation, shredders, grinders, and other tools where contaminated surfaces or part of a component is mechanically removed.

A system for processing large streams of tritium waste has been proposed.

The systems depicted in Figure 5 employs mechanical and physical processes for size reduction and tritium decontamination. This industrial sized system is designed to remove tritium, to background and nearbackground levels, for a variety of soft housekeeping components at the rate of tens of $\mathrm{kg}$ per hour. In this system tritium is removed from the effluent waste stream and concentrated in a collection system which can be either disposed of or processed for reuse.

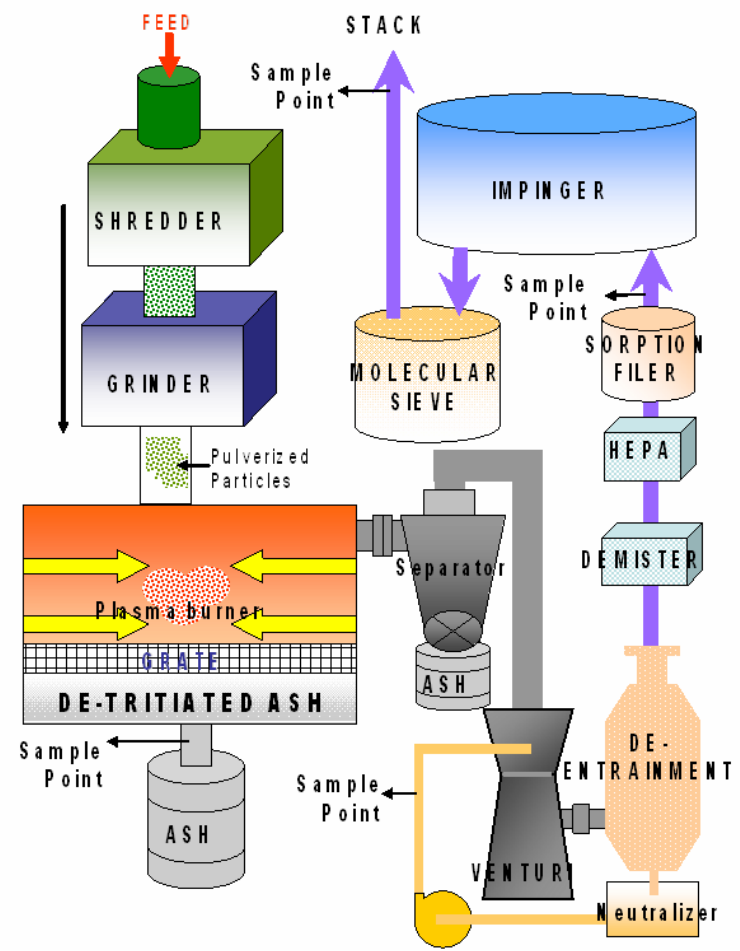

Fig. 5 Soft and Semi-Soft Tritium Decontamination Processing System

The three major categories of tritium decontamination/removal which include; chemical, physical, and mechanical (or combinations of the three methods) are effective, but are highly dependent on the type item and acceptable end condition of the item.

For small to medium components with irregular shapes (small tools, diagnostic equipment, etc), chemical, physical, and mechanical techniques which include oxidative chemistry and heat appear to be most effective for tritium decontamination or in some instances the removal of highly tritiated sub-components from the object.

For flat surfaces such as first wall materials in fusion energy devices (vacuum vessels or chambers), physical removal by means of a Nd:YAG laser appear to be rapid and cost effective. In areas where walls or floor surfaces need to be decontaminated, $\mathrm{CO}_{2}$ ablation has been effective. For items that need to be disposed of in the most economically efficient way, mechanical (shredding) followed by intense heat can effectively remove tritium from the waste stream and jointly reduce volume.

For purposes associated with the removal of tritium for disposal a system is required for complete or nearly complete removal of tritium from a variety of components and multiple processes need to be employed. 
Table II details the various methods in a comparison and evaluation format. Each tritium decontamination method has specific advantages germane to the material or component that requires tritium removal. In all listed cases, good tritium DF's are realized. The decontamination methodology is primarily determined by the material requiring decontamination, and the required condition of that material after the decontamination process. None of these methods can truly be classified as non-destructive. Although the level of disrepair during the decontamination process for the various components may be considered insignificantly low from the point of material damage.

TABLE II.

Comparison and Evaluation Table

\begin{tabular}{|c|c|c|c|}
\hline Method & Chemical & Physical & Mechanical \\
\hline Type & $\begin{array}{c}\text { Oxidative } \\
\text { Chemistry, } \\
\text { Chelating } \\
\text { Agents }\end{array}$ & $\begin{array}{l}\text { Lasers, } \\
\text { Ovens, } \\
\text { Burners }\end{array}$ & $\begin{array}{c}\mathrm{CO}_{2} \text { pellets, } \\
\text { cutting } \\
\text { devices }\end{array}$ \\
\hline Application & $\begin{array}{l}\text { Hydrogen } \\
\text { Peroxide, } \\
\text { Ozone }\end{array}$ & $\begin{array}{c}\text { Nd:YAG, } \\
\text { UV, Oven } \\
\text { Heating }\end{array}$ & $\begin{array}{l}\text { Ablation } \\
\text { removal }\end{array}$ \\
\hline Cost & Low & $\begin{array}{l}\text { Medium/ } \\
\text { High }\end{array}$ & $\begin{array}{c}\text { Low/ } \\
\text { Medium }\end{array}$ \\
\hline $\begin{array}{c}\text { Deployment } \\
\text { Material }\end{array}$ & $\begin{array}{c}\text { Metal, } \\
\text { ceramics, } \\
\text { Flat } \\
\text { Surfaces, } \\
\text { Soft Waste }\end{array}$ & $\begin{array}{l}\text { First wall } \\
\text { materials } \\
\text { (graphite, } \\
\text { stainless } \\
\text { steel) }\end{array}$ & $\begin{array}{c}\text { Walls, } \\
\text { Floors, } \\
\text { Building } \\
\text { Compounds }\end{array}$ \\
\hline Effectiveness & Good & Very Good & Good \\
\hline
\end{tabular}

\section{CONCLUSIONS}

A variety of technologies exist for the removal of tritium contamination. The method or technique employed is highly dependent on the type of material to be decontaminated, the distribution of tritium contamination, the concentration of tritium, and the final acceptable condition of the item. No single technology will serve as a method for efficient and cost effective tritium decontamination of all items. The deployment of a combination of the described methods provides a powerful synergy for tritium decontamination/removal in support of fusion energy development.

\section{ACKNOWLEDGEMENTS}

The authors of this paper would like to acknowledge the contribution of the PPPL Environmental Restoration Group and the PPPL Health Physics Group. In addition, appreciation is expressed to collaborators from the Los Alamos National Laboratory and international collaborators working on tritium decontamination and safe handling technologies at Karlsruhe
Forschungszentrum, Tritium Laboratory Karlsruhe (TLK), the Joint European Tokamak (JET), and the Japan Atomic Energy Research Institute (JAERI), Tritium Engineering Laboratory (TEL). Funding for this work was provided by the United States Department of Energy (DOE), Contract No. DE-AC02-76CH03073.

\section{REFERENCES}

[1] R. R. M. Moormann, H. K. Hinssen, C. H. Wu Oxidation of Carbon Based First Wall Materials of ITER. 18th International Atomic Energy Agency Fusion Energy Conference, Sorrento, Italy, 4-10 October 2000.

[2] C. A. Gentile, G. L. Guttadora, J. J. Parker Oxidative Tritium Decontamination System, Invention No. 01- 1812-1, United States Patent and Trademark Office, submitted May 2001.

[3] L. Bartlein, S. Konishi, R. V. Carlson, M. Enoeda, R. S. Willms, K. Okuno Decontamination Studies of Japan Atomic Energy Research Institute Fuel Cleanup System and Glovebox Installed at the Tritium Systems Test Assembly. IEEE Journal 07803-2969-4/95. (1995).

[4] C. A. Gentile, et. al. Tritium Decontamination of TFTR D-T Graphite Tiles Employing Ultra Violet Light and a Nd:YAG Laser 18th IEEE/NPSS Symposium on Fusion Engineering. October 25-29, 1999, Albuquerque, New Mexico.

[5] $22^{\text {nd }}$ Tritium Focus Group Meeting, C. H. Skinner, N. Bekris, J. P. Coad, C. A. Gentile, R. Reiswig, S. Wilms, October 8-10, 2002, Princeton Plasma Physics Laboratory. 


\section{External Distribution}

Plasma Research Laboratory, Australian National University, Australia

Professor I.R. Jones, Flinders University, Australia

Professor João Canalle, Instituto de Fisica DEQ/IF - UERJ, Brazil

Mr. Gerson O. Ludwig, Instituto Nacional de Pesquisas, Brazil

Dr. P.H. Sakanaka, Instituto Fisica, Brazil

The Librarian, Culham Laboratory, England

Mrs. S.A. Hutchinson, JET Library, England

Professor M.N. Bussac, Ecole Polytechnique, France

Librarian, Max-Planck-Institut für Plasmaphysik, Germany

Jolan Moldvai, Reports Library, Hungarian Academy of Sciences, Central Research Institute for Physics, Hungary

Dr. P. Kaw, Institute for Plasma Research, India

Ms. P.J. Pathak, Librarian, Institute for Plasma Research, India

Ms. Clelia De Palo, Associazione EURATOM-ENEA, Italy

Dr. G. Grosso, Instituto di Fisica del Plasma, Italy

Librarian, Naka Fusion Research Establishment, JAERI, Japan

Library, Laboratory for Complex Energy Processes, Institute for Advanced Study, Kyoto University, Japan

Research Information Center, National Institute for Fusion Science, Japan

Dr. O. Mitarai, Kyushu Tokai University, Japan

Dr. Jiangang Li, Institute of Plasma Physics, Chinese Academy of Sciences, People's Republic of China

Professor Yuping Huo, School of Physical Science and Technology, People's Republic of China

Library, Academia Sinica, Institute of Plasma Physics, People's Republic of China

Librarian, Institute of Physics, Chinese Academy of Sciences, People's Republic of China

Dr. S. Mirnov, TRINITI, Troitsk, Russian Federation, Russia

Dr. V.S. Strelkov, Kurchatov Institute, Russian Federation, Russia

Professor Peter Lukac, Katedra Fyziky Plazmy MFF UK, Mlynska dolina F-2, Komenskeho Univerzita, SK-842 15 Bratislava, Slovakia

Dr. G.S. Lee, Korea Basic Science Institute, South Korea

Institute for Plasma Research, University of Maryland, USA

Librarian, Fusion Energy Division, Oak Ridge National Laboratory, USA

Librarian, Institute of Fusion Studies, University of Texas, USA

Librarian, Magnetic Fusion Program, Lawrence Livermore National Laboratory, USA

Library, General Atomics, USA

Plasma Physics Group, Fusion Energy Research Program, University of California at San Diego, USA

Plasma Physics Library, Columbia University, USA

Alkesh Punjabi, Center for Fusion Research and Training, Hampton University, USA

Dr. W.M. Stacey, Fusion Research Center, Georgia Institute of Technology, USA

Dr. John Willis, U.S. Department of Energy, Office of Fusion Energy Sciences, USA

Mr. Paul H. Wright, Indianapolis, Indiana, USA 
The Princeton Plasma Physics Laboratory is operated by Princeton University under contract with the U.S. Department of Energy.

\author{
Information Services \\ Princeton Plasma Physics Laboratory \\ P.O. Box 451 \\ Princeton, NJ 08543
}

Phone: 609-243-2750

Fax: 609-243-2751

e-mail: pppl_info@pppl.gov

Internet Address: http://www.pppl.gov 